\title{
Optimization of Gas Turbine Cogeneration System for Various Heat Exchanger Configurations
}

\author{
M. Costea ${ }^{1 *}$, M. Feidt ${ }^{2}$, G. Alexandru ${ }^{1}$ and D. Descieux ${ }^{2}$ \\ 1 Department of Engineering Thermodynamics, University Politehnica of Bucharest, Splaiul Independentei 313, 060042 Bucharest - Romania \\ 2 ENSEM-LEMTA, University Henri Poincaré of Nancy, 2 avenue de la Forêt de Haye, 54516 Vandoeuvre-lès-Nancy - France \\ e-mail: liana5802@yahoo.fr - michel.feidł@ensem.inpl-nancy.fr - gabriela_al_83@yahoo.com - damien-descieux@lermab.uhp-nancy.fr \\ * Corresponding author
}

\begin{abstract}
Résumé - Optimisation des systèmes de turbine à combustion en cogénération pour différentes configurations des échangeurs de chaleur - Cet article explore et compare les performances des trois configurations de systèmes de turbine à combustion permettant la production combinée de chaleur et d'électricité, sur la base du cycle irréversible régénératif de Brayton-Joule. Le modèle proposé est développé pour deux contraintes différentes sur le cycle, notamment le flux de chaleur produit par combustion imposé ou la température maximale du cycle imposée. Le modèle considère également l'irréversibilité due au frottement dans le compresseur et la turbine et celle due aux pertes de chaleur dans la chambre de combustion et les échangeurs de chaleur. Le rendement au sens du premier principe du système sans et avec cogénération et le rendement exergétique rendent compte des avantages de la cogénération, et aident le concepteur à choisir la meilleure configuration de turbines à combustion en fonction de ses besoins. Des données expérimentales d'une microturbine opérationnelle ont été utilisées pour valider le modèle. La puissance fournie et les rendements au sens du premier principe et exergétique sont optimisés par rapport à un ensemble de paramètres de fonctionnement. Les valeurs optimales des paramètres du moteur à turbine à combustion qui correspondent au maximum de puissance fournie, respectivement au maximum de rendement thermodynamique sont discutées. Les résultats montrent que la plupart des performances maximales correspondent aux mêmes valeurs optimales du taux de compression pour le flux imposé, sauf le rendement exergétique maximum qui demande des valeurs plus élevées du taux de compression que celles pour le maximum du flux d'exergie. Une comparaison des performances de ces trois configurations et les perspectives sont proposées.
\end{abstract}

\begin{abstract}
Optimization of Gas Turbine Cogeneration System for Various Heat Exchanger Configurations - The present paper investigates and compares the performance of three configurations of Gas Turbine systems allowing cogeneration of heat and electricity, on the basis of an irreversible regenerative Brayton-Joule cycle. The proposed model is developed for two different cycle constraints, namely, an imposed heat transfer rate released by the fuel combustion, or an imposed maximum cycle temperature. The model also includes the irreversibility due to the friction in the compressor and turbine, and due to the heat losses in the combustion chamber and heat exchangers. Energy efficiency for the system without and with cogeneration, and the exergetic efficiency are used in order to emphasize the cogeneration advantages, but also to help the designer to choose the best configuration of the Gas Turbine system that suits to his needs. Experimental data from a real operating microturbine were used to validate the model. The power output and the energy and exergetic efficiencies are optimized with respect to a set of operating parameters. The optimum values of the Gas Turbine engine parameters
\end{abstract}


corresponding to maximum power output and respectively to maximum thermodynamic efficiency are discussed. The results show same optimal values of the compression ratio corresponding to almost all maximum performances for an imposed heat transfer rate released by the fuel combustion, excepting the maximum exergetic efficiency that requires higher optimal values of the compression ratio than the maximum exergy rate one. A performance comparison of the three configurations is done and future perspectives of the work are proposed.

\section{LIST OF SYMBOLS}

A Quantity relative to air $\left(\mathrm{kg} \cdot \mathrm{s}^{-1}\right)$

$\dot{C} \quad$ Heat capacity rate (W.K $\mathrm{K}^{-1}$ )

$D, d \quad$ External and inner tube diameter of the combustion chamber $(\mathrm{m})$

$\dot{E x} \quad$ Exergy transfer rate (W)

$F \quad$ Quantity relative to fuel $\left(\mathrm{kg} . \mathrm{s}^{-1}\right)$

$h \quad$ Heat transfer coefficient $\left(\mathrm{W} \cdot \mathrm{m}^{-2} \cdot \mathrm{K}^{-1}\right)$

$K \quad$ Heat transfer conductance $\left(\mathrm{W} . \mathrm{K}^{-1}\right)$

$k \quad$ Conductivity $\left(\mathrm{W} \cdot \mathrm{m}^{-1} \cdot \mathrm{K}^{-1}\right)$

$L \quad$ Length (m)

$L H V \quad$ Low heating value of the fuel $(\mathrm{J} / \mathrm{kg})$

$\dot{m} \quad$ Mass flow rate $\left(\mathrm{kg} . \mathrm{s}^{-1}\right)$

$\mathrm{Nu} \quad$ Nusselt number

$\dot{Q} \quad$ Heat transfer rate (W)

$S \quad$ Heat transfer surface $\left(\mathrm{m}^{2}\right)$

$T \quad$ Temperature (K)

$\dot{W} \quad$ Mechanical power output (W)

\section{Greek symbols}

$\Phi \quad$ Fuel/air equivalence ratio

$\beta \quad$ Cycle parameter related to $\tau_{c}$

$\varepsilon \quad$ Effectiveness

$\gamma \quad$ Specific heat ratio

$\eta \quad$ Efficiency

$\theta$ Flue gases ratio going into the useful heat exchanger/ heat recuperator

$\tau \quad$ Compression ratio

\section{Subscripts}

$\begin{array}{ll}a & \text { Air } \\ C & \text { Cold } \\ c c & \text { Combustion chamber } \\ \text { comp } & \text { Compression } \\ \text { CHP } & \text { Cogeneration } \\ E & \text { Electricity } \\ e n t & \text { Entry } \\ e x & \text { Exergetic } \\ f & \text { Fuel } \\ f g & \text { Flue gas }\end{array}$

$\begin{array}{ll}H E & \text { Heat exchanger } \\ l & \text { Lost } \\ r & \text { Recuperator } \\ r e f & \text { Reference } \\ s & \text { Stoechiometric } \\ T & \text { Turbine } \\ t & \text { Total } \\ u & \text { Useful } \\ u i & \text { Water inlet in the useful HE } \\ u o & \text { Water outlet from the useful HE } \\ w & \text { Wall } \\ I & \text { First law, or related to energy }\end{array}$

Abbreviations

CHP Combined Heat and Power

ECE External Combustion Engine

FC Fuel Cell

GT Gas Turbine

ICE Internal Combustion Engine

PV/T Photo Voltaic/Thermal

VT Vapor Turbine

\section{INTRODUCTION}

Cogeneration may be defined as the simultaneous production of electrical or mechanical energy and useful thermal energy from a single energy source, by capturing or applying heat from an exhaust gas that would otherwise be rejected to the environment. It is also called CHP system (Combined Heat and Power Production). In general, CHP systems are usually operated using two basic strategies: following the electric load and following the thermal load. In the case of the electric load operation strategy, the prime mover is loaded in order to satisfy the electric demand of the facility through the generator. The waste heat from this loading is then recovered in order to satisfy the thermal load of the facility. For the thermal load operation strategy, the prime mover is loaded such that the recovered waste heat will be adequate to supply the facility with the necessary thermal energy to satisfy the heating requirements. For this operating strategy, the amount of electricity produced is a by-product that may provide the electricity required by the consumer or may be transferred to the grid. 
Cogeneration plant can operate at efficiencies greater than those achieved when heat and power are produced in separate or distinct processes. For example, efficiency values pass from $35-40 \%$ for electrical or mechanical production, to $80-$ $85 \%$ for the cogeneration system efficiency [1]. The environmental issue should be also considered as an important cogeneration system trump with respect to carbon dioxide emissions, which are mainly responsible of the greenhouse effect. It has been shown that using natural gas for firing, the carbon dioxide emissions are significantly diminished [1] (by $20 \%$ when compared to fossil fuel combustion, by $40 \%$ when compared to coal combustion).

The sizes and applications of CHP systems vary to a considerable degree, ranging in size from a few kilowatts to megawatts of power production, with applications to residential, commercial, industrial, or large-scale district energy systems [1]. However, some operation issues should be accounted for. First, the electricity and heat demand have to match the cogeneration unit capacity. Then, the fact that the fuel used in cogeneration systems varies from fossil fuels (natural gas, coal) to hydrogen and methanol [1]. Eventually, the costs of installation, operation and maintenance and respectively of fuel have to be considered.

Four main types of cogeneration systems are used nowadays, being able to cover the specific energy demand of the consumers:

- Steam Turbine Engines;

- Gas Turbine Engines (combustion turbines);

- Internal Combustion Engines;

- Fuel Cells [2] (most recently).

Other configurations are possible and currently developed, particularly the hybrid ones and the Combined Cycles (CC).

The present paper focuses on Gas Turbine system configurations. After a careful analysis of what has been done in the past, and owing to the new tendencies in term of applications (microturbines) and new technological opportunities, the various criteria used to qualify the cogeneration systems are examined and some of them are applied to evaluate and optimize three main configurations that are explored. The theoretical model developed and adapted to each configuration is then validated based on experimental data of a real operating microturbine. The comparison of the three configuration performances provides results helping the designer to choose the most appropriate configuration that would meet the consumer demand.

\section{GAS TURBINES AND MICROCOGENERATION}

\subsection{State of Art}

A Gas Turbine (GT), and particularly the combustion turbine, is a rotating machine that converts the heat from a hot gas flow produced in a combustion chamber into mechanical energy.

The two main uses of GT are the electricity production and, since 1940, the aeronautical powering [3]. Hereafter, the paper focuses on terrestrial applications. Whatever the use would be, thermodynamics appears as an essential tool for studying and improving Gas Turbines and polygeneration systems performance [4-8].

During the last twenty years, the Gas Turbine industry has known a continuous improvement, conveying to emissions and cost reduction, respectively efficiency enhancement. Many researches and studies have been dedicated to CHP systems. Some of them aim to compare the performance, for example, of a complex Brayton cycle under maximum ecological and maximum economic conditions [9], completed by a thermodynamic analysis and parametric study [10] of this cycle where reheat is added, others discuss Gas Turbine performance enhancement by intake air cooling [11], or inlet air cooling and evaporative after cooling of the compressor discharge [12]. Results of optimization criteria or methods are very often reported, such as power optimization of an irreversible closed intercooled regenerated Brayton cycle coupled to variable temperature reservoirs $[13,14]$ or energetic and exergetic efficiency analysis of an indirect fired air turbine Combined Heat and Power System [15]. Many exergy analyses of cogeneration systems [16-19] have been reported and pointed out their advantages. In addition, outside approaches to the main topic are also important, such as investment criteria for the cogeneration plants [20], which add an economical point of view, solar applications used to reduce carbon dioxide emissions [21], or exergoenvironmental analysis using Multimodal Genetic Algorithm [22].

An overview of the previous works shows that the earliest ones were relative to closed cycle Gas Turbines in contact with constant temperature source and sink [23] or used in solar power plants [24]. Further studies extended the results to regenerative cycle [25], and finite heat capacity source and sink [26]. A recent book reviews the main operating experiences and future potential [27]. Recently, the corresponding model for open cycle Gas Turbine was proposed [28]. It considers two main cases: a) when the heat delivered by the combustion is imposed, and $b$ ) when the maximum temperature of the cycle is imposed (blade material constraint).

The study and design of microturbines or nanoturbines represents the new tendency [29]. Due to technical and economical progress, experimentation [30] and demonstrator [31] are actually studied and developed. Also the control and investigation of distributed generation effects are provided for a few networks using micro or nanoturbines all over the world (Japan, Germany). The power range of these machines varies from 1 to $80 \mathrm{~kW}_{\mathrm{e}}$ for microturbines, and less for nanoturbines [29]. They can use several fuel types, are less polluting and have low maintenance costs. 
The present paper aims to investigate and compare some configurations of the Gas Turbines systems allowing cogeneration of heat and electricity, on the basis of an irreversible regenerative Brayton-Joule cycle. Its main application regards the CHP with microturbines.

\subsection{Performance Evaluation Criteria}

Various criteria for performance evaluation of the cogeneration systems are currently used. The widespread one is the efficiency that is differently expressed depending on its aim and reference [32]. Three efficiency types are generally used for a cogeneration system performance evaluation and comparison.

The energy efficiency of the cogeneration system, $\eta_{I, \text { CHIP }}$, based on the First Law of Thermodynamics and including both useful effects, power and heat transfer rate covering the thermal load of the facility, is expressed by:

$$
\eta_{I, C H P}=\frac{\dot{W}_{C H P}+\dot{Q}_{u, C H P}}{\dot{Q}_{f, C H P}}
$$

It becomes the energy efficiency without cogeneration, $\eta_{I, E}$, when only electricity is produced:

$$
\eta_{I, E}=\frac{\dot{W}_{E}}{\dot{Q}_{f, C H P}}
$$

The third one is the exergetic efficiency, $\eta_{e x}$, being the only one that involves the energy quality. Its expression for the cogeneration system is defined as:

$$
\eta_{e x}=\frac{\dot{W}_{C H P}+\dot{E} x_{u, C H P}}{\dot{E} x_{f, C H P}}
$$

When compared cogeneration to separate operation strategies allowing the same useful effects the classical definition of the relative fuel consumption factor, fuel savings, and Fuel Energy Saving Ratio (FESR) results, the last one being expressed as:

$$
F E S R=1-\frac{\dot{Q}_{f, C H P}}{\dot{Q}_{f, r e f}}
$$

The last term of the right side of Equation (4) represents the relative fuel consumption factor.

Similarly, there are many economic criteria, namely costs per unit of energy (based on the First Law of Thermodynamics), energetic cost for power $\dot{W}$ and useful heat rate $\dot{Q}_{u}$, or cost per unit of exergy product.

The suggestion is that the general use of the exergy criterion would be the best way for assessing cogeneration plants. The approach developed here intents to argue this view by comparing three main heat exchanger configurations in the cogeneration system.

\section{GAS TURBINE CONFIGURATION ALTERNATIVE FOR COGENERATION}

The traditional Gas Turbine engine contains three main components: compressor, combustion chamber and turbine. An essential improvement of the cycle efficiency is assured when a heat recuperator in the Brayton-Joule cycle is added [14]. The problem generated by the presence of this new heat exchanger is to find its optimal position relative to the useful heat exchanger in the Gas Turbine system.

Air is compressed in the compressor between 15 and 40 bar. Then, it enters the combustion chamber where the fuel is injected and burned after being compressed at least at the same pressure as the air. The flue gases exiting the combustion chamber at a high temperature $\left(850^{\circ} \mathrm{C}\right.$ to $1200^{\circ} \mathrm{C}$, sometimes more) expand in the turbine which could be connected to an alternator that transforms the mechanical power into electrical one. At the turbine exit, the flue gases still have a high temperature $\left(450^{\circ} \mathrm{C}\right.$ to $\left.550^{\circ} \mathrm{C}\right)$ and can therefore be further used. One of the utilizations can be to preheat the compressed air before its entrance in the combustion chamber. Another possible use can be to heat water or a used medium for different needs.

\section{General Presentation of the Configuration Alternatives of the System}

The Gas Turbine Engine (GTE) analyzed here operates upon the Brayton cycle that is a constant pressure combustion cycle named after George Brayton, the American engineer who developed it. The cycle consists of two adiabatic and two isobaric processes illustrated in Figure 1 together with

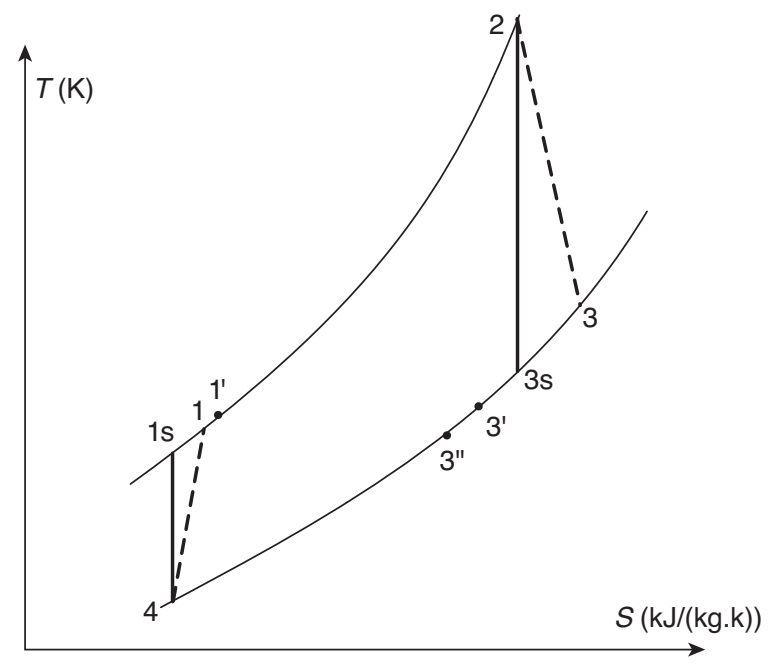

Figure 1

$T-S$ diagram of the Brayton cycle. 


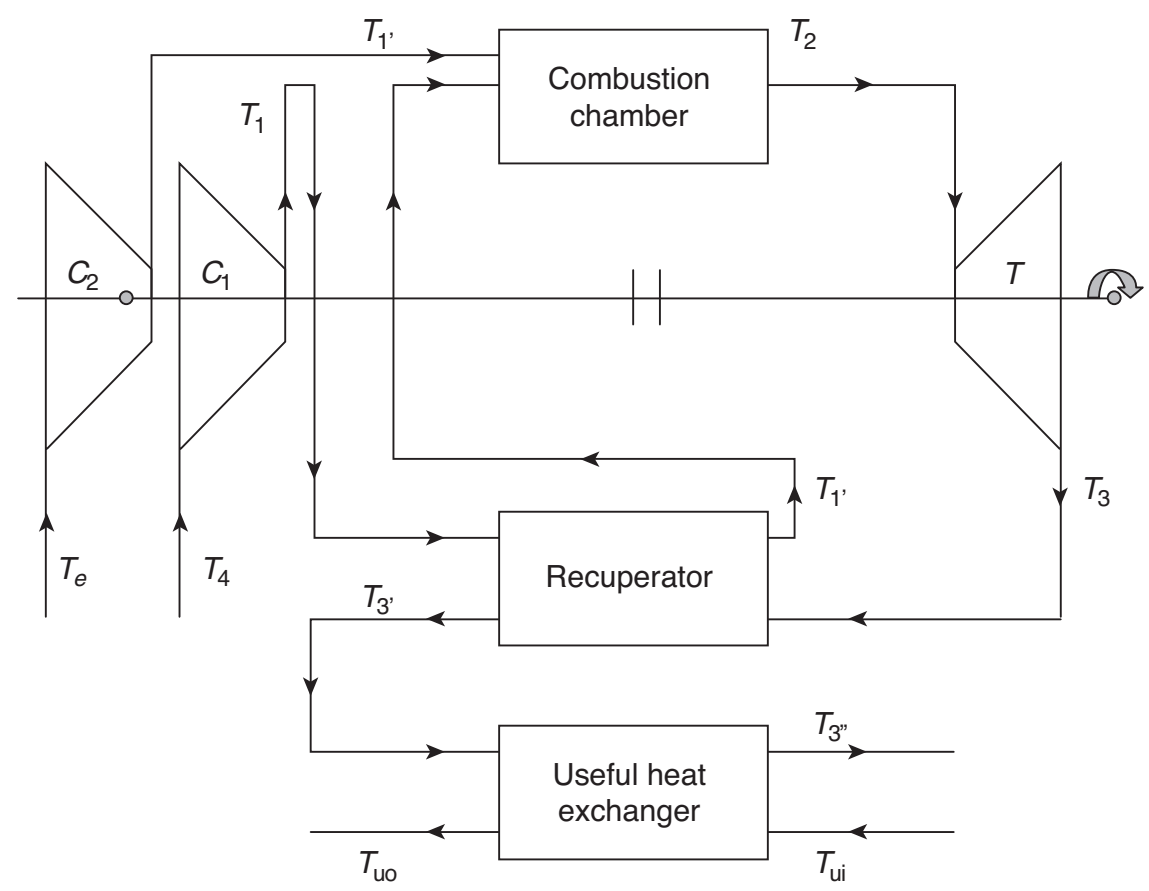

Figure 2

Scheme of the configuration where the recuperator is connected upstream of the useful heat exchanger.

the characteristic states corresponding to the configuration alternatives of the system. Thus, the process $4-1$ s corresponds to the isentropic compression in the compressor, being replaced in the real operating cycle by $4-1$, the nonisentropic compression. When using a heat recuperator to preheat the compressed air before entering the combustion chamber based on the heat potential of the flue gases, the combustion corresponds to process 1' -2 . It is followed by the non-isentropic expansion in the turbine, process $2-3$ in the real cycle, compared to the isentropic one, $2-3 \mathrm{~s}$. The other states pointed out on the cycle representation correspond to the exit of the heat recuperator and entrance in the useful heat exchanger, state 3', respectively the exit of the useful heat exchanger, state 3".

The Gas Turbine Engine analysis performed in this paper is based on the real model of microturbine technology for Combined Heat and Power generation, Turbec T100 [33] produced by Turbec Company. A careful analysis of the technical information provided by the Turbec Company for this GTE model conveyed to the configuration presented in Figure 2 as being the closest approximation of the real model.

Besides the 3 basic components of the Gas Turbine Engine, namely the compressors $\left(\mathrm{C}_{1}\right.$ for air and $\mathrm{C}_{2}$ for fuel), the combustion chamber and the turbine, two heat exchangers have been added in the CHP system. The first heat exchanger is used to preheat the compressed air before entering the combustion chamber. The hot flue gases exiting the turbine provide the heat transferred to the air during their passage through this heat exchanger. Therefore, a part of the heat that would have been lost at the turbine exit is recuperated in this heat exchanger, which will be referred to as heat recuperator.

Another part of the heat taken away from the cycle by the flue gases could be used for other purpose, i.e. to heat the water needed in a hot water industrial installation. This part will be called the useful heat and, hence, the second heat exchanger will be called useful heat exchanger.

In the configuration presented above, the heat recuperator is located up-stream of the useful heat exchanger. By using this configuration model, the results are comparable with those recorded for the experimental model of Turbec T100 [33].

This work proposes other approaches of the cogeneration system configuration: one where the heat recuperator is connected down-stream of the useful heat exchanger and another one, where the heat recuperator and the useful heat exchanger are connected in parallel. These two configurations are presented in Figures 3 and 4. 


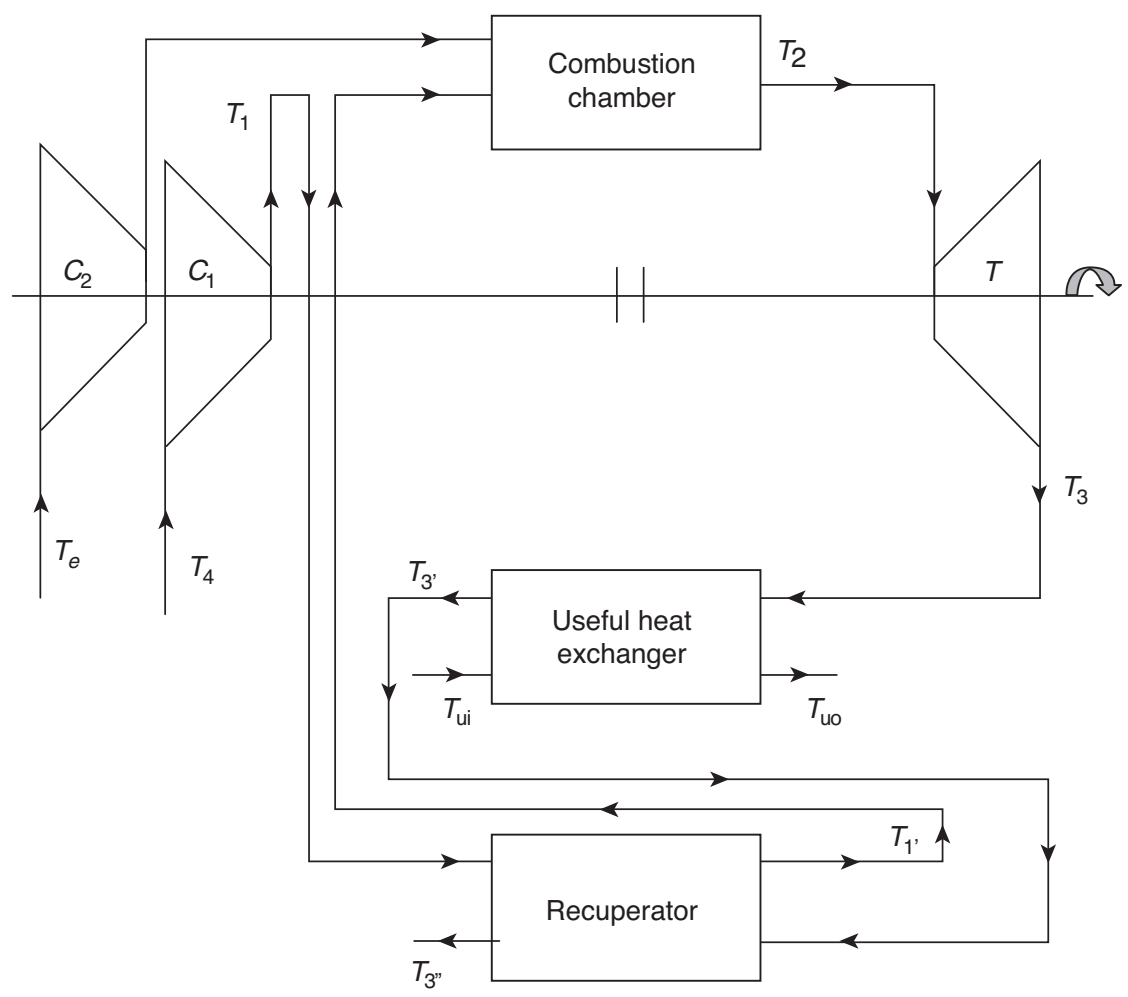

Figure 3

Scheme of the configuration where the recuperator is connected downstream of the useful heat exchanger, with 3' - exit of the useful heat exchanger, entrance in the heat recuperator, 3 " - exit of the heat recuperator.

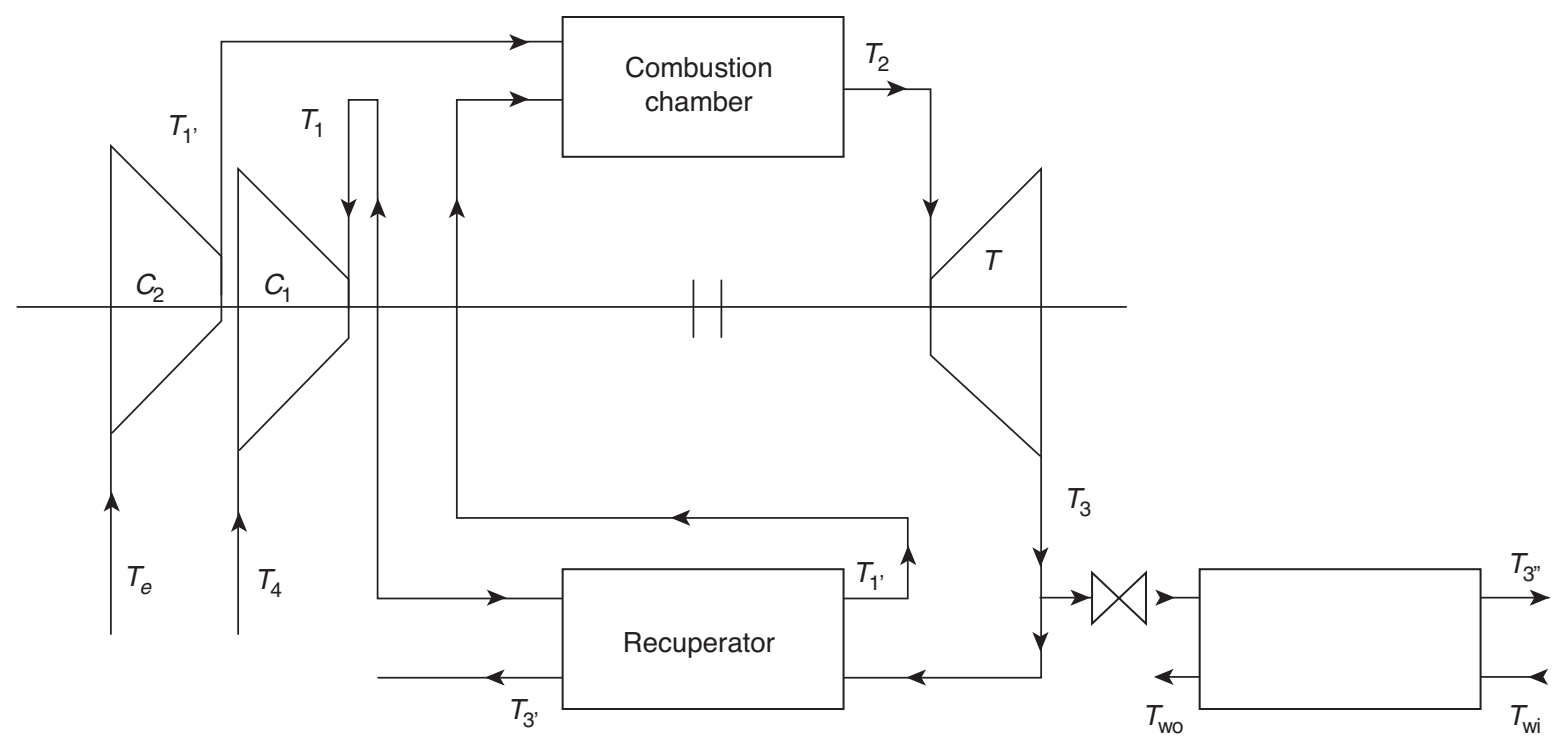

Figure 4

Scheme of the configuration where the heat recuperator and the useful heat exchanger are connected in parallel, with 3 ' - exit of the heat recuperator, 3" - exit of the useful heat exchanger. 


\section{MATHEMATICAL MODEL OF THE COGENERATION SYSTEM}

The mathematical model of the Gas Turbine Engine was developed considering two realistic operation conditions of the cogeneration system. The first one is mainly related to an economic issue of GTE, namely to a limitation of the operation cost of the system by an imposed heat transfer rate released by the fuel combustion in the combustion chamber. Actually, it is equivalent to a limited fuel consumption in the combustion chamber, for which optimum performance is sought, if there exists. The second one derives from turbine material thermal strength and is formulated as an imposed maximum temperature of the cycle, which corresponds to the flue gas temperature entering the turbine.

As the cogeneration system has several components and hence, the model involves even not negligible calculations, the following basic assumptions have been adopted in order to simplify the model:

- the fuel burned is natural gas, supposed perfectly mixed in the air after entering the combustion chamber;

- the pressure losses are neglected throughout the system;

- the perfect gas laws are used;

- the combustion chamber is modeled as a concentric tube annulus and the corresponding equations are used;

- the heat recuperator and useful heat exchanger effectiveness are considered to be equal and both heat exchangers are considered in counter flow;

- the quantity of fuel in the fuel/air mixture is given by the fuel/air equivalence ratio, $\Phi$, which is defined as [34]:

$$
\Phi=\frac{F / A_{\text {actual }}}{F / A_{s}}
$$

Knowing that $F / A_{\text {actual }}=\frac{\dot{m}_{f}}{\dot{m}_{a}}$ relating the mass flow rate of the fuel to the actual air mass flow rate, and that the Stoechiometric Fuel/Air ratio for natural gas is $F / A_{s}=0.069$, we can say that the mass flow rate of fuel entering the combustion chamber is given by:

$$
\dot{m}_{f}=\Phi \cdot \dot{m}_{a} \cdot\left(F / A_{s}\right)
$$

The flue gases mass flow rate results from the mass conservation equation as:

$$
\dot{m}_{f g}=\dot{m}_{f}+\dot{m}_{a}
$$

The mathematical model of the cogeneration system is mainly based on:

- the first law of thermodynamics;

- the second law of thermodynamics;

- the heat transfer law;

- together with component and process corresponding equations.

\subsection{Cogeneration with an Imposed Transfer Rate from the Hot Source}

\subsubsection{Case with the Recuperator Connected Upstream of the Useful Heat Exchangers}

This configuration is the most common one [35], so it will be used as reference for the set of equations that are describing the complete model for each GTE component:

\section{The Air Compressor}

The air temperature at the exit of the compressor results from the irreversible adiabatic process equation:

$$
T_{1}=T_{4}\left[\frac{\beta-1}{\eta_{\text {comp }, a}}+1\right]
$$

where the cycle parameter $\beta=\tau_{C}^{\frac{\gamma-1}{\gamma}}$ contains the compression ratio $\tau_{C}=p_{2} / p_{1}$, and the ratio of the specific heats at constant pressure and constant volume, $\gamma$.

The shaft work of the air compressor can be computed as:

$$
\dot{W}_{\text {comp }, a}=\dot{C}_{a}\left(T_{1}-T_{4}\right)
$$

\section{The Fuel Compressor}

Fuel is injected in the combustion chamber at the same pressure and temperature as the air in state 1'. That is why, before the injection, it is submitted to an adiabatic compression from the atmospheric pressure and the storage temperature, $T_{f}$, to the needed values of these parameters. The shaft work of the fuel compressor is expressed as:

$$
\dot{W}_{\text {comp }, f}=\dot{C}_{f}\left(T_{1}-T_{f}\right)
$$

\section{The Combustion Chamber}

It has been modeled as an equivalent tube-annulus made of steel, which has the maximum allowable temperature of 755.38 K [35].

Neglecting the conductive heat transfer through the walls, and considering inside an arithmetic average temperature of the air, the following expression for the combustion chamber walls temperature [35] was derived:

$$
T_{w}=\frac{\frac{T_{1^{\prime}}+T_{2}}{2} h_{f g}+T_{4} h_{a}}{h_{f g}+h_{a}}
$$

The heat delivered by combustion has been computed for the chemical reaction of methane and air using the fuel/air equivalence ratio definition given by Equation (5).

In order to find out the temperatures at the entrance and exit of the combustion chamber and at the exit of the turbine, which are interdependent due to the recuperator location, a system of three equations with three unknowns, $T_{1}, T_{2}, T_{3}$, was solved (with the help of MAPLE software). 
The first equation of the system is represented by the energy balance inside the combustion chamber:

$$
\dot{Q}_{1^{\prime}-2}=\dot{m}_{f} \cdot L H V-K_{l w}\left(\frac{T_{1^{\prime}}+T_{2}}{2}-T_{w}\right)
$$

where the thermal conductance of the heat losses through the combustion chamber walls and the corresponding heat transfer surface are:

$$
\begin{aligned}
& K_{l w}=h_{f g} \cdot S_{c c} \\
& S_{c c}=\pi \cdot D \cdot L
\end{aligned}
$$

When looking to the heat transfer rate of the combustion chamber final product, Equation (12) can be expressed as:

$$
\dot{Q}_{1^{\prime}-2}=\dot{C}_{f g}\left(T_{2}-T_{1^{\prime}}\right)
$$

where $\dot{C}_{f g}$ is the heat capacity rate of the flue gas. This heat capacity rate has been chosen after checking that the difference introduced with reference to the heat capacity rate of fuel air mixture is less than $1 \%$.

The second equation of the above mentioned system contains the expression of the temperature at the entrance of the combustion chamber that results from the heat recuperator effectiveness, $\varepsilon_{r}$, expression as:

$$
T_{1^{\prime}}=T_{1}\left(1-\varepsilon_{r}\right)+\varepsilon_{r} T_{3}
$$

\section{The Turbine}

The system last equation gives the temperature expression at the exit of the turbine:

$$
T_{3}=T_{2}\left[1+\eta_{T}(\beta-1)\right]
$$

\section{The Heat Recuperator}

The recuperator is modeled as a counter flow heat exchanger where the flue gas releases the heat that is transferred to the air. The thermal balance of this heat exchanger considered to have no thermal losses led to the following expression for the exit temperature of the recuperator:

$$
T_{3^{\prime}}=T_{3}-\frac{\dot{C}_{a}}{\dot{C}_{f g}}\left(T_{1^{\prime}}-T_{1}\right)
$$

\section{The Useful Heat Exchanger}

Following the heat recuperator model, the useful heat exchanger was also considered as a counter flow heat exchanger. This time, its effectiveness expression yielded the exit temperature of this device as:

$$
T_{3^{\prime \prime}}=T_{3^{\prime}}\left(1-\varepsilon_{u}\right)+\varepsilon_{u} T_{u i}
$$

Based on Equations (18) and (19), the useful heat transfer rate transferred by the flue gas inside this heat exchanger is mainly a function of $T_{3}$ :

$$
\dot{Q}_{u}=\dot{C}_{f g}\left(T_{3^{\prime}}-T_{3^{\prime \prime}}\right)=\dot{C}_{f g} \varepsilon_{u}\left[T_{3}-\frac{\dot{C}_{a}}{\dot{C}_{f g}}\left(T_{1^{\prime}}-T_{1}\right)+T_{u i}\right]
$$

In this case, the heat transfer rate rejected to the sink will be given by:

$$
\dot{Q}_{3^{\prime \prime}-4}=\dot{C}_{f g}\left(T_{3^{n}}-T_{4}\right)
$$

\section{Energy and Exergy Transfer Rate}

By using the energy transfer rate balance of the cycle and considering that the work produced in the turbine is partially used to rotate the shafts of the two compressors, the expression of the mechanical power that can be further transformed in electrical one yields:

$$
\dot{W}=\dot{Q}_{1^{\prime}-2}-\dot{Q}_{u}-\dot{Q}_{3^{\prime \prime}-4}
$$

Then, the total useful energy transfer rate pull together the power output and the useful heat transfer rate:

$$
\dot{E}_{t}=\dot{W}+\dot{Q}_{u}
$$

The useful exergy transfer rate is also used as a performance indicator of the cogeneration system. Based on previous equations, it results as:

$$
\dot{E} x_{u}=\dot{Q}_{u}\left[1-\frac{T_{4} \ln \left(T_{3^{\prime}} / T_{3^{\prime \prime}}\right)}{T_{3^{\prime}}-T_{3^{\prime \prime}}}\right]
$$

Similarly, the entry exergy transfer rate is:

$$
\dot{E} x_{e n t}=\dot{Q}_{f}\left[1-\frac{T_{4} \ln \left(T_{2} / T_{1^{\prime}}\right)}{T_{2}-T_{1^{\prime}}}\right]
$$

Eventually, for a global assessment of the CHP useful effect quality, the total exergy transfer rate will be used:

$$
\dot{E} x_{t}=\dot{W}+\dot{E} x_{u}
$$

\section{Efficiencies}

Besides the energy transfer rates previously introduced, several efficiencies are presented hereafter in order to analyze the model results. Each kind of efficiency involves one of the above definitions of the energy transfer rates, as follows:

- the total efficiency without cogeneration (mechanical efficiency):

$$
\eta_{I}=\frac{\dot{W}}{\dot{Q}_{f}}
$$

- the first law cogeneration efficiency:

$$
\eta_{I, C H P}=\frac{\dot{W}+\dot{Q}_{u}}{\dot{Q}_{f}}
$$

- the exergetic efficiency relative to the entry exergy transfer rate available on the flue gas:

$$
\eta_{e x}=\frac{\dot{E} x_{t}}{\dot{E} x_{e n t}}
$$


- the useful heat/power ratio, HP:

$$
H P=\frac{\dot{Q_{u}}}{\dot{W}}
$$

As previously mentioned, the HP ratio is an important parameter of the system.

\subsubsection{Case with the Recuperator Connected Downstream of the Useful Heat Exchanger}

In order to determine the corresponding temperatures in this new configuration $\left(T_{1}, T_{2}, T_{3}, T_{3}, T_{3}\right.$, - see Fig. 3), the balance equation of the combustion chamber $(E q .12)$ from the previous model is conserved, as well as Equation (17) that represents the expression of the temperature at the turbine exit. Then, the following equations are added to the model:

- the expression of the temperature at the exit of the useful heat exchanger:

$$
T_{3^{\prime}}=T_{3}-\varepsilon_{u}\left(T_{3}-T_{u i}\right)
$$

- the expression of the temperature at the entrance in the combustion chamber:

$$
T_{1}=T_{1}+\varepsilon_{r}\left(T_{3^{\prime}}-T_{1}\right)
$$

- the temperature at the exit of the recuperator:

$$
T_{3^{\prime \prime}}=T_{3^{\prime}}-\varepsilon_{R}\left(T_{3^{\prime}}-T_{1}\right) \frac{\dot{C}_{a}}{\dot{C}_{f g}}
$$

All other definitions remain valid excepting those introducing the heat transfer rate exchanged in the recuperator and the useful heat transfer rate:

$$
\dot{Q}_{r}=\dot{C}_{f g}\left(T_{3^{\prime}}-T_{3^{\prime \prime}}\right) / \dot{Q}_{u}=\dot{C}_{f g}\left(T_{3}-T_{3^{\prime}}\right)
$$

and the useful exergy transfer rate expression:

$$
\dot{E} x_{u}=\dot{Q}_{u}\left[1-\frac{T_{4} \ln \left(T_{3} / T_{3^{\prime}}\right)}{T_{3}-T_{3^{\prime}}}\right]
$$

\subsubsection{Case with the Recuperator Connected in Parallel with the Useful Heat Exchanger}

In this case, a valve splits the amount of the flue gases coming out of the turbine into a part that goes into the recuperator, and a part that goes into the useful heat exchanger. The proportion of these two streams is given by a parameter $\theta$ that varies between 1 when all the flue gases go into the useful heat exchanger, and zero when all the flue gases go into the heat recuperator, depending on the electrical power load or heating load.

For this particular configuration, the calculation first step is to find out which of the hot and cold fluids passing through the recuperator has the minimum heat capacity rate:

$$
\dot{C}_{r \min }=\min \left[(1-\theta) \dot{C}_{f g}, \dot{C}_{a}\right]
$$

The expression of the air temperature at the entrance in the combustion chamber yields from the energy balance equation of the recuperator as:

$$
T_{1^{\prime}}=T_{1}+\frac{\varepsilon_{r} \dot{C}_{r \min }\left(T_{3}-T_{1}\right)}{\dot{C}_{a}}
$$

Other temperatures are determined as follows:

- the temperature of the flue gas at the heat recuperator exit:

$$
T_{3^{\prime}}=T_{3}-\frac{\varepsilon_{R} \dot{C}_{r \min }\left(T_{3}-T_{1}\right)}{(1-\theta) \dot{C}_{f g}}
$$

- the temperature at the useful heat exchanger exit:

$$
T_{3^{\prime \prime}}=T_{3}-\varepsilon_{u}\left(T_{3}-T_{u}\right)
$$

Correspondingly, the useful heat transfer rate is given by:

$$
\dot{Q}_{u}=\varepsilon_{u} \theta \dot{C}_{f g}\left(T_{3}-T_{u}\right)
$$

and the total heat transfer rate to the sink is computed as:

$$
\dot{Q}_{C}=(1-\theta) \dot{C}_{f g}\left(T_{3^{\prime}}-T_{4}\right)+\theta \dot{C}_{f g}\left(T_{3^{n}}-T_{4}\right)
$$

The useful exergy transfer rate becomes:

$$
\dot{E} x_{u}=\dot{Q}_{u}\left[1-\frac{T_{4} \ln \left(T_{3} / T_{3^{\prime \prime}}\right)}{T_{3}-T_{3^{\prime \prime}}}\right]
$$

Thus, one can numerically determine all cycle temperatures and the system performance in terms of heat transfer rates and efficiencies.

\subsection{Cogeneration with an Imposed Maximum Temperature}

An important constraint to the cycle operation conditions is imposed by the materials used in the Gas Turbine Engine [35], especially at the exit of the combustion chamber and inlet of the turbine, where the highest temperature in the cycle is reached. Hence, the following models have been developed using the maximum temperature of the cycle, $T_{2}$, as a given value.

\subsubsection{Case with the Recuperator Connected Upstream of the Useful Heat Exchanger}

This time the fuel/air equivalence ratio, $\Phi$, is not anymore a model parameter. It is replaced by the parameter $T_{2}=T_{\max }=$ $1223 \mathrm{~K}$. All equations used in the previous case remain valid here as well, but some of them will provide different properties as compared to the case with imposed heat transfer rate from the source. So, the value of $\Phi$ is computed by solving the system of equations consisting of:

- the energy balance equation inside the combustion chamber, (Eq. 12, 15);

- the expression of $T_{1}$, the temperature at the exit of the compressor, (Eq.8);

- the expression of $T_{1}$, the temperature at the entrance in the combustion chamber, (Eq. 16); 
- the expression of $T_{3}$, the temperature at the exit of the turbine, (Eq. 17).

The solution of this system provides all temperatures of the cycle (see Fig. 2) and the mass flow rate of fuel entering in the combustion chamber. Then, the flue gases mass flow rate $(E q .7)$ can be computed, followed by all heat transfer rates and efficiencies previously introduced.

\subsubsection{Case with the Recuperator Connected Downstream of the Useful Heat Exchanger}

Similarly to the case with the recuperator connected downstream of the useful heat exchanger, same equations are used as in the case with imposed heat transfer rate. The fuel/air equivalence ratio is computed this time after solving the following system of equations:

- the energy balance equation inside the combustion chamber, (Eq. 12, 15);

- the expression of $T_{1}$, the temperature at the exit of the compressor, (Eq. 8);

- the expression of $T_{1}$, the temperature at the entrance in the combustion chamber, (Eq. 32);

- the expression of $T_{3}$, the temperature at the exit of the turbine, (Eq. 17);

- the expression of $T_{3}$, the temperature at the exit of the useful exchanger, (Eq.31);

- the expression of $T_{3}$,", the temperature at the exit of the recuperator, $(E q .33)$.

Furthermore, the computation follows the same steps as for the previous case, namely Equations (7, 9, 35, 23, 36, 26-30) are used in order to get the results corresponding to this case.

\subsubsection{Case with the Recuperator and the Useful Heat Exchanger are Connected in Parallel}

Similarly to the case with the recuperator connected downstream of the useful heat exchanger, same equations are used as in the case with imposed heat transfer rate. The fuel/air equivalence ratio is computed this time after solving the following system of equations:

- the energy balance equation inside the combustion chamber, (Eq. 12, 15);

- the expression of $T_{1}$, the temperature at the exit of the compressor, (Eq. 8);

- the expression of $T_{1}$, the temperature at the entrance in the combustion chamber, (Eq. 38);

- the expression of $T_{3}$, the temperature at the exit of the turbine, (Eq. 17);

- the expression of $T_{3}$, the temperature at the exit of the recuperator, (Eq. 39);

- the expression of $T_{3}$ ", the temperature at the exit of the useful exchanger, (Eq. 40).

Once the cycle temperatures (see Fig. 4) determined, the cogeneration system performance can be computed by using Equations $(9,41,23,43,26-30)$.

\section{RESULTS}

\subsection{Cogeneration with an Imposed Heat Transfer Rate from the Hot Source}

\subsubsection{Case with the Recuperator Connected Upstream of the Useful Heat Exchangers}

\section{Validation of the Model}

The first step before proceeding to numerical calculations for each of the six cases chosen for study was to get a validation of the model. As this case with the recuperator connected upstream of the useful heat exchangers is the closed one to the Turbec T100 Gas Turbine Engine configuration, the model equations have been introduced in the Maple software and input data of this GTE [33] have been considered, as follow: $T_{4}=298 \mathrm{~K}, T_{u i}=323 \mathrm{~K}, L H V=45 \mathrm{MJ} / \mathrm{kg}$, $\dot{m}_{a}=0.79 \mathrm{~kg} / \mathrm{s}, \eta_{\text {comp }, a}=\eta_{T}=0.80, D=700 \mathrm{~mm}, d=200 \mathrm{~mm}$, $L=800 \mathrm{~mm}, \gamma=1.4, T_{f}=303 \mathrm{~K}, M_{f}=16.7 \mathrm{~kg} / \mathrm{kmol}$, $\tau_{c}=4.5, \varepsilon_{r}=\varepsilon_{u}=0.9, \Phi=0.13$.

The air, fuel and flue gases properties are considered at the mean temperature in the system, namely $950 \mathrm{~K}$ : $c_{p, a}=1131 \mathrm{~J} / \mathrm{kg} . \mathrm{K}, c_{p f}=4348 \mathrm{~J} / \mathrm{kg} . \mathrm{K}, \mu=411.3 \times 10^{-7}$ $\mathrm{N} \mathrm{s} / \mathrm{m}^{2}, \operatorname{Pr}=0.723, k=0.0643 \mathrm{~W} / \mathrm{m} . \mathrm{K}, c_{p, \mathrm{~N}_{2}}=1157 \mathrm{~J} / \mathrm{kg} . \mathrm{K}$, $c_{p, \mathrm{CO}_{2}}=1220 \mathrm{~J} / \mathrm{kg} . \mathrm{K}, c_{p, \mathrm{H}_{2} \mathrm{O}}=2252 \mathrm{~J} / \mathrm{kg} . \mathrm{K}, c_{p, \mathrm{O}_{2}}=1082 \mathrm{~J} / \mathrm{kg} . \mathrm{K}$.

A comparison of the theoretical model results obtained with the above mentioned data and the real operating data for Turbec T100 is presented in Table 1.

\section{TABLE 1}

Comparison between Turbec T100 performance [33] and the theoretical model results

\begin{tabular}{c|c|c|c|c|c}
\hline & $\dot{W}(\mathrm{~kW})$ & $\dot{Q}(\mathrm{~kW})$ & $\eta_{I}(\%)$ & $\eta_{I, C H P}(\%)$ & $T_{\max }(\mathrm{K})$ \\
\hline Model results & 92.4 & 180.3 & 28.9 & 85.2 & 1109 \\
\hline $\begin{array}{c}\text { Real operating data } \\
\text { from Turbec T100 }\end{array}$ & 100 & 155 & 30 & 77 & 1223 \\
\hline
\end{tabular}

Some differences in the range of $4-16 \%$ can be observed between the experimental data and theoretical ones at this stage of the model. They are due to fuel composition, isentropic efficiencies, and temperature approximations (supposed data) that are used and to the assumptions aiming to simplify the theoretical model. These assumptions refer to average specific heats instead of temperature dependent ones, no pressure drops, no mechanical power losses. Further development of the model will remove these assumptions conveying to more accurate theoretical data.

For a further analysis of the model, the inlet temperature in the useful heat exchanger has been increased from $323 \mathrm{~K}$ to $490 \mathrm{~K}$, due to some constraints imposed by the configuration with the recuperator connected downstream from the heat exchanger. The same input data will be used for all cases, in order to make a final comparison of the three configurations performances. 


\section{Results}

\section{- Maximum Power, Energy and Exergy Rates}

The model equations have shown that the mechanical power output depends on four parameters: compression ratio $\tau_{c}$, fuel/air equivalence ratio $\Phi$, combustion chamber wall temperature $T_{w}$, and heat exchanger effectiveness (supposed the same for convenience) $\varepsilon_{r}=\varepsilon_{u}=\varepsilon$. The variation ranges of these parameters for the numerical calculations were respectively: $\tau_{c}=[1 ; 40], \Phi=[0.07 ; 1]$, $T_{w}<755.4 \mathrm{~K}, \varepsilon=[0.5 ; 1]$.

In fact, during calculations, an inferior limit of $\Phi$ appears when the mechanical power decreases to 0 . Its corresponding value is near of 0.075. Similarly, the compression and expansion ratios (supposed the same; no pressure losses at first attempt) exhibit a superior limit which must not be overcame in order to assure a normal operation of the recuperator (air coming out of compressor is heated by the flue gas).

Classically for a given $\Phi$ value, there is an optimal value of the compression ratio for which maximum power output is attained. An illustration of the energy transfer rates variation versus the compression ration for a fuel/air equivalence ratio of 0.4 is presented in Figure 5. It shows that maximum values are reached for the mechanical power output and for the total energy transfer rate, but for different corresponding values of the compression ratio. The useful heat transfer rate presents a different behavior, due to the fact that it is complementary to the mechanical power output, when looking to the total energy transfer rate.

Overviews of the results corresponding to an imposed heat transfer rate to the source are presented in Tables 2 and 3. For the moment, only the upstream configuration result comments are given hereafter. It can be observed that the optimum value of $\tau_{c}$ for which maximum values of the performance are attended increases with the fuel/air ratio,

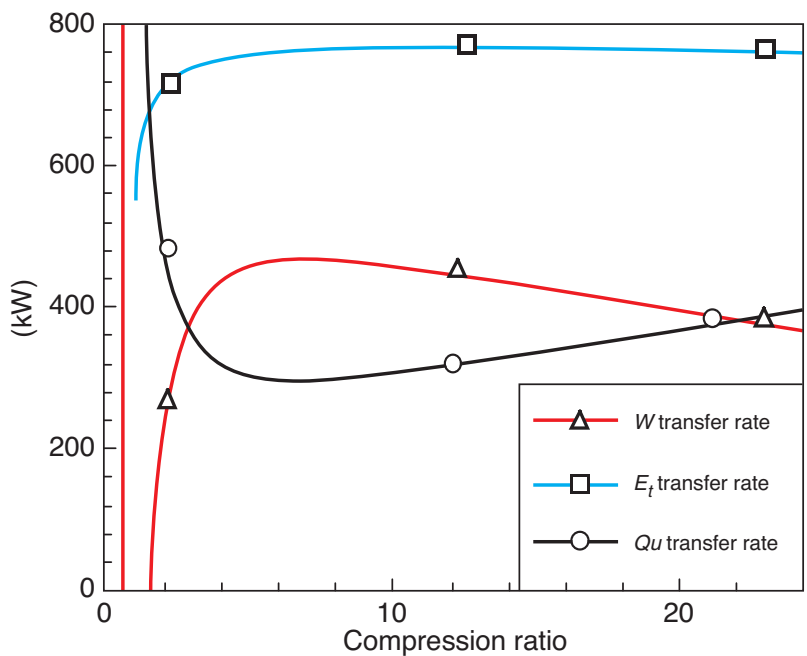

Figure 5

Mechanical power output and energy rates evolution as a function of the compression ratio (heat transfer rate at the source imposed, upstream configuration, $\Phi=0.4$ ).

and the mechanical power produced is almost twice the useful heat transfer rate when looking to the HP ratio in the power optimization columns (Tab.2).

The evolution of the maximum values of the total energy transfer rate presents the same tendency as the mechanical power, with the difference that higher corresponding values of the compression ratio are registered. The obtained results confirm previous publication results [36].

With the maximum values for the total exergy transfer rate, the optimum compression ratio reached the lowest values compared to those of the previous performance above mentioned.

TABLE 2

Cogeneration optimization for an imposed heat transfer rate at the heat source, for the three configurations - energy and exergy rate optimization

\begin{tabular}{|c|c|c|c|c|c|c|c|c|c|c|c|c|c|}
\hline & \multirow[b]{2}{*}{$\begin{array}{c}\Phi \\
(-)\end{array}$} & \multicolumn{4}{|c|}{ Power optimization } & \multicolumn{4}{|c|}{ Energy rate optimization } & \multicolumn{4}{|c|}{ Exergy rate optimization } \\
\hline & & $\begin{array}{l}\tau_{c} \\
(-)\end{array}$ & $\begin{array}{c}\operatorname{Max} \dot{W} \\
(\mathrm{~kW})\end{array}$ & $\begin{array}{c}\text { HP ratio } \\
(-)\end{array}$ & $\begin{array}{c}\eta_{I} \\
(\%)\end{array}$ & $\begin{array}{l}\tau_{c} \\
(-)\end{array}$ & $\begin{array}{c}\operatorname{Max} \dot{E}_{t} \\
(\mathrm{~kW})\end{array}$ & $\begin{array}{c}\text { HP ratio } \\
(-)\end{array}$ & $\begin{array}{c}\eta_{I, C H P} \\
(\%)\end{array}$ & $\begin{array}{c}\tau_{c} \\
(-)\end{array}$ & $\begin{array}{c}\operatorname{Max} \dot{E} x_{t} \\
(\mathrm{~kW})\end{array}$ & $\begin{array}{c}\text { HP ratio } \\
(-)\end{array}$ & $\begin{array}{l}\eta_{e x} \\
(\%)\end{array}$ \\
\hline \multirow{3}{*}{$\begin{array}{c}\mathrm{Up} \\
\text { stream }\end{array}$} & 0.2 & 3.6 & 204.5 & 0.40 & 41.7 & 5.6 & 289.3 & 0.53 & 58.9 & 3.2 & 251 & 0.40 & 63.5 \\
\hline & 0.3 & 5.2 & 341.7 & 0.50 & 46.4 & 8.4 & 515.4 & 0.59 & 70 & 4.4 & 446 & 0.50 & 72 \\
\hline & 0.4 & 7 & 471 & 0.53 & 49.1 & 11 & 722.9 & 0.59 & 75.3 & 5.4 & 629 & 0.54 & 76 \\
\hline \multirow{3}{*}{$\begin{array}{l}\text { Down } \\
\text { stream }\end{array}$} & 0.2 & 4.6 & 85.8 & 2.54 & 17.5 & \multirow{3}{*}{\multicolumn{4}{|c|}{ No optimum }} & \multirow{3}{*}{\multicolumn{4}{|c|}{ No optimum }} \\
\hline & 0.3 & 7.4 & 165.9 & 1.88 & 22.5 & & & & & & & & \\
\hline & 0.4 & 10.2 & 250.3 & 1.58 & 26 & & & & & & & & \\
\hline \multirow{3}{*}{$\begin{array}{c}\text { Parallel } \\
\text { stream }\end{array}$} & 0.2 & 6.4 & 121 & 1.09 & 24.7 & \multicolumn{4}{|c|}{ No optimum } & 2.2 & 215 & 2.74 & 64.3 \\
\hline & 0.3 & 10.6 & 236.2 & 0.84 & 32.1 & 1.6 & 507.4 & 6.15 & 68.9 & 3 & 386 & 1.92 & 70 \\
\hline & 0.4 & 15 & 352 & 0.72 & 36.7 & 2 & 689.1 & 3.76 & 71.8 & 3.8 & 552 & 1.56 & 73 \\
\hline
\end{tabular}


TABLE 3

Cogeneration optimization for an imposed heat transfer rate at the heat source, for the three configurations - efficiency optimization

\begin{tabular}{|c|c|c|c|c|c|c|c|}
\hline & \multirow[b]{2}{*}{$\Phi$} & \multicolumn{2}{|c|}{ Optimization of $\eta_{I}$} & \multicolumn{2}{|c|}{ Optimization of $\eta_{I, C H P}$} & \multicolumn{2}{|c|}{ Optimization of $\eta_{e x}$} \\
\hline & & $\tau_{c}(-)$ & $\operatorname{Max} \eta_{I}(\%)$ & $\tau_{c}(-)$ & $\operatorname{Max} \eta_{I, C H P}(\%)$ & $\tau_{c}(-)$ & $\operatorname{Max} \eta_{e x}(\%)$ \\
\hline \multirow{3}{*}{$\begin{array}{c}\text { Up } \\
\text { stream }\end{array}$} & 0.2 & 3.6 & 44.6 & 5.6 & 58.9 & 4.6 & 65 \\
\hline & 0.3 & 5.2 & 46.4 & 8.4 & 70 & 6.6 & 73.1 \\
\hline & 0.4 & 7 & 49.1 & 11 & 75.3 & 8.4 & 77 \\
\hline \multirow{3}{*}{$\begin{array}{l}\text { Down } \\
\text { stream }\end{array}$} & 0.2 & 4.6 & 17.5 & \multirow{3}{*}{\multicolumn{2}{|c|}{ No optimum }} & \multirow{3}{*}{\multicolumn{2}{|c|}{ No optimum }} \\
\hline & 0.3 & 7.4 & 22.5 & & & & \\
\hline & 0.4 & 10.2 & 26 & & & & \\
\hline \multirow{3}{*}{$\begin{array}{c}\text { Parallel } \\
\text { stream }\end{array}$} & 0.2 & 6.4 & 24.6 & \multicolumn{2}{|c|}{ No optimum } & 2.6 & 64.4 \\
\hline & 0.3 & 10.6 & 32 & 1.6 & 69 & 3.6 & 70.2 \\
\hline & 0.4 & 15 & 36.6 & 2 & 71.7 & 4.8 & 73.1 \\
\hline
\end{tabular}

Table 2 also gives the efficiencies achieved for each optimum value of the compression ratio to which corresponds maximum power output, or total energy transfer rate, or total exergy transfer rate. All values of the efficiencies are increasing with the fuel/air equivalence ratio. For a given value of the fuel/air equivalence ratio, the values increase when passing from the energy efficiency without cogeneration to the energy efficiency with cogeneration, and then to the exergetic efficiency.

\section{- Maximum Efficiencies}

The maximum values of the energy efficiency without and with cogeneration, and the exergetic efficiency in function of the compression ratio and fuel/air equivalence ratio are indicated in Table 3.

As expected, the optimization of the energy efficiency without and with cogeneration records the same values as for the energy transfer rate optimization. These results are accurate since the efficiency definition involves besides the useful effect, the heat transfer rate to the source, the last one being imposed, so having a fixed value for this studied case. Only the exergetic efficiency optimization registers higher values for the efficiency compared to those indicated in Table 2, as well as for the corresponding optimal compression ratio. Also, note that for all given values of the fuel/air equivalence ratio, the highest value of the optimum compression ratio $\left(\tau_{c}=11\right)$ corresponds to the maximum of the energy efficiency with cogeneration, $\eta_{I, C H P}=75.3 \%$.

\subsubsection{Case with the Recuperator Connected Downstream of the Useful Heat Exchangers}

In this case, the recuperator works in a correct manner only when the flue gases entrance temperature, $T_{3}$, overcomes the air temperature at its entrance, $T_{1}$. Consequently, an inferior limit for the water inlet temperature, $T_{u i}$, should be determined in connection with the parametric conditions (compression ratio, fuel/air ratio, combustion chamber wall temperature [35]). This limit increases with the compression ratio and decreases with fuel/air ratio when the recuperator effectiveness is lower than 1. Also, it was found that the influence of the combustion chamber wall temperature on the inferior limit for the water inlet temperature is negligible, and the limit of $\Phi$ is 0.078 , very close to the preceding case one.

\section{Maximum Power, Energy and Exergy Rates}

The maximum power produced in the same conditions is much lower than for the preceding configuration (Tab. 2), while the corresponding optimal values for the compression ratio are higher. For example, one gets for this configuration $\dot{W}_{\text {max }}=165.9 \mathrm{~kW}$ for $\tau_{c}=7.4$, compared to $\dot{W}_{\max }=341.7 \mathrm{~kW}$ for $\tau_{c}=5.2$ for the previous one. Nevertheless, this drastic reduction of the mechanical power output is compensated by the useful heat rate, as shows the HP ratio values. Furthermore, there isn't any optimum total energy rate. It decreases monotonously with the compression ratio. The same evolution is registered for the total exergy rate variation.

\section{Efficiencies}

This first law with cogeneration efficiency and the exergetic efficiency do not have an optimum in function of the compression ratio $(T a b .3)$. For the energy efficiency without cogeneration, same remarks as for the previous configuration are valid here as well.

Thus, excepting the heat to power ratio HP, the evolution of the energy and exergy rates together with that of the efficiencies confirms that this configuration is not really effective when the heat transfer rate to the source is fixed.

\subsubsection{Case with the Recuperator Connected in Parallel with the Useful Heat Exchanger}

Using the same set of input data and a "fair" distribution of the flue gases between the two heat exchangers (see Fig. 4) given by $\theta=0.5$, the same inferior limit yields for the fuel/air ratio as previously (around 0.075 ). 

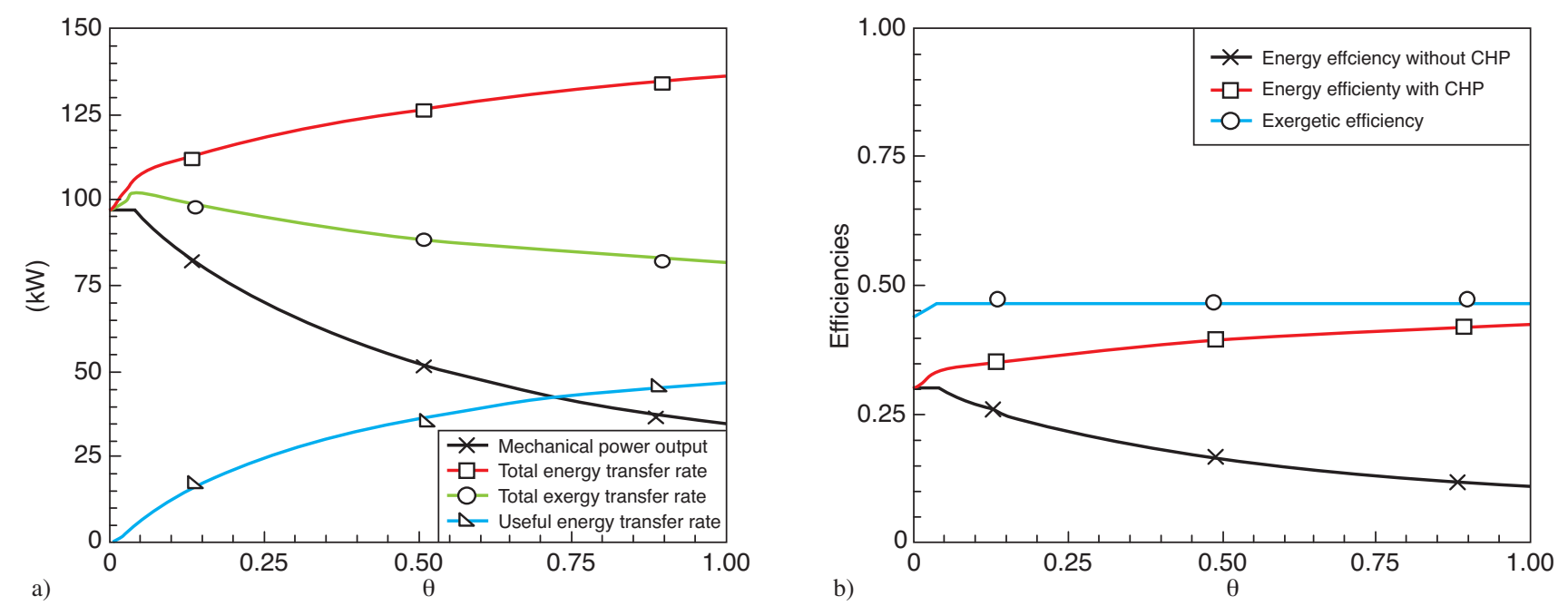

Figure 6

Evolution of a) energy and exergy rates, and b) efficiencies in function of $\theta$ (heat transfer rate at the source imposed, parallel configuration).

\section{Maximum Power, Energy and Exergy Rates}

This time, the maximum mechanical power values are intermediate between the values obtained in the two preceding cases, but they are reached for the highest optimum compression ratio. Data presented in Table 2 also show that the maximum values for the total energy and exergy transfer rate are obtained for smaller values of the compression ratio than for the earlier cases. It explains why the heat to power ratio is much higher than in other cases. This configuration is favorable when more useful heat transfer rate is needed than mechanical power, which becomes a by-product. Note that for small values of the fuel/air equivalence ratio there isn't any optimization of the total energy transfer rate. Figure 6a illustrates the energy and exergy rates evolution as a function of $\theta$.

One can see that although the useful energy transfer rate and the total energy transfer rate increase with $\theta$, the total exergy transfer rate, and the mechanical power mainly decrease. The same situation holds for the efficiencies (Fig. $6 b$ ). Hence, higher mechanical power is required, smaller $\theta$ value has to be chosen, for which also higher exergy transfer rate is registered. The advantage of this configuration consists in the ability to vary $\theta$ depending on the facility needs (electrical power or heat).

Note that all curves illustrated in the figures are calculated and the markers are only used for identification purpose.

\section{Efficiencies}

All the three efficiencies show maximum value in function of the compression ratio (Tab.3), for $\Phi>0.2$. These maximum values increase when passing from the energy efficiency without cogeneration to the exergetic efficiency, together with the corresponding optimum compression ratio. Contrarily, the efficiencies do not show maximum value in function of $\theta$ (Fig. $6 b$ ). Although, one notices that the energy efficiency with cogeneration increases with $\theta$, while exergetic efficiency shows highest values and it is almost constant on the variation range of $\theta$.

\subsection{Cogeneration with an Imposed Maximum Temperature}

\subsubsection{Case with the Recuperator Connected Upstream of the Useful Heat Exchanger}

When imposing the maximum temperature of the cycle, an inferior limit of it appears in order to preserve a positive value of the mechanical power output. A value around $717 \mathrm{~K}$ was found for this limit.

\section{Maximum Power, Energy and Exergy Rates (Tab.4)}

The mechanical power output reaches a maximum for values of the compression ratio that increase with the maximum temperature of the cycle, but the $H P$ ratio increases more pronounced with $T_{\max }$ than it did with $\Phi$. The optimum values for the exergy transfer rate are obtained for higher values of the compression ratio than those corresponding to optimum values of the maximum mechanical power. The useful heat transfer rate is higher than the mechanical power, as the $H P$ ratio shows. There is no optimum regime for the total energy transfer rate, which continuously increases with the compression ratio.

\section{Efficiencies (Tab. 5)}

Maximum energy efficiency occurs for a lower compression ratio than that for maximum power. The two regimes of maximum power and maximum efficiency are significantly different. The obtained results confirm recent publication results $[37,38]$. 
TABLE 4

Cogeneration optimization for an imposed maximum temperature, for the three configurations - energy and exergy rate optimization

\begin{tabular}{|c|c|c|c|c|c|c|c|c|c|c|c|c|c|}
\hline & & \multicolumn{4}{|c|}{ Power optimization } & \multicolumn{4}{|c|}{ Energy rate optimization } & \multicolumn{4}{|c|}{ Exergy rate optimization } \\
\hline & $\begin{array}{l}T_{\max } \\
(\mathrm{K})\end{array}$ & $\tau_{c}$ & $\begin{array}{c}\operatorname{Max} \dot{W} \\
(\mathrm{~kW})\end{array}$ & $\begin{array}{c}\text { HP } \\
\text { ratio (-) }\end{array}$ & $\begin{array}{c}\eta_{I} \\
(\%)\end{array}$ & $\tau_{c}$ & $\begin{array}{c}\operatorname{Max} \dot{E}_{t} \\
(\mathrm{~kW})\end{array}$ & $\begin{array}{c}\text { HP ratio } \\
(-)\end{array}$ & $\begin{array}{c}\eta_{I, C H P} \\
(\%)\end{array}$ & $\tau_{c}$ & $\begin{array}{c}\operatorname{Max} \dot{E} x_{t} \\
(\mathrm{~kW})\end{array}$ & $\begin{array}{c}\text { HP } \\
\text { ratio (-) }\end{array}$ & $\begin{array}{l}\eta_{e x} \\
(\%)\end{array}$ \\
\hline \multirow{3}{*}{$\begin{array}{c}\text { Up } \\
\text { stream }\end{array}$} & 1000 & 4.2 & 68.3 & 0.35 & 24.5 & \multirow{3}{*}{\multicolumn{4}{|c|}{ No optimum }} & 6.6 & 86.3 & 1.24 & 41.5 \\
\hline & 1500 & 9.4 & 209.6 & 0.79 & 35.6 & & & & & 16 & 299.9 & 1.22 & 61.7 \\
\hline & 2500 & 17.6 & 395.1 & 0.78 & 41.7 & & & & & 31.4 & 573.6 & 1.08 & 69.8 \\
\hline \multirow{3}{*}{$\begin{array}{l}\text { Down } \\
\text { stream }\end{array}$} & 1000 & 4.2 & 48.6 & 4.14 & 11.3 & \multirow{3}{*}{\multicolumn{4}{|c|}{ No optimum }} & \multirow{3}{*}{\multicolumn{4}{|c|}{ No optimum }} \\
\hline & 1500 & 9 & 181 & 2.17 & 20.5 & & & & & & & & \\
\hline & 2500 & 16.2 & 368 & 1.56 & 26.8 & & & & & & & & \\
\hline \multirow{3}{*}{$\begin{array}{c}\text { Parallel } \\
\text { stream }\end{array}$} & 1000 & 4 & 70 & \multirow{3}{*}{\multicolumn{2}{|c|}{-}} & 1 & 200 & \multirow{3}{*}{\multicolumn{2}{|c|}{-}} & 3.8 & 120 & \multirow{3}{*}{\multicolumn{2}{|c|}{-}} \\
\hline & 1500 & 10 & 210 & & & 4 & 450 & & & 4.5 & 350 & & \\
\hline & 2500 & 16 & 400 & & & 6.5 & 730 & & & 8 & 620 & & \\
\hline
\end{tabular}

TABLE 5

Cogeneration optimization for an imposed maximum temperature, for the three configurations - efficiency optimization

\begin{tabular}{|c|c|c|c|c|c|c|c|}
\hline & \multirow[b]{2}{*}{$T_{\max }(\mathrm{K})$} & \multicolumn{2}{|c|}{ Optimization of $\eta_{I}$} & \multicolumn{2}{|c|}{ Optimization of $\eta_{I, C H P}$} & \multicolumn{2}{|c|}{ Optimization of $\eta_{e x}$} \\
\hline & & $\tau_{c}$ & $\operatorname{Max} \eta_{I}$ & $\tau_{c}$ & $\operatorname{Max} \eta_{I, C H P}$ & $\tau_{c}$ & $\operatorname{Max} \eta_{e x}$ \\
\hline \multirow{3}{*}{$\begin{array}{c}\text { Up } \\
\text { stream }\end{array}$} & 1000 & 2.6 & 27.2 & \multirow{3}{*}{\multicolumn{2}{|c|}{ No optimum }} & 5.8 & 52 \\
\hline & 1500 & 4.4 & 39.2 & & & 10.4 & 70.6 \\
\hline & 2500 & 6.8 & 45.5 & & & 16.6 & 77.8 \\
\hline \multirow{3}{*}{$\begin{array}{l}\text { Down } \\
\text { stream }\end{array}$} & 1000 & 4.2 & 11.3 & \multirow{3}{*}{\multicolumn{2}{|c|}{ No optimum }} & \multirow{3}{*}{\multicolumn{2}{|c|}{ No optimum }} \\
\hline & 1500 & 9.2 & 20.5 & & & & \\
\hline & 2500 & 16.4 & 26.8 & & & & \\
\hline \multirow{3}{*}{$\begin{array}{l}\text { Parallel } \\
\text { stream }\end{array}$} & 1000 & 4.2 & 18 & 2 & 36 & 2 & 58 \\
\hline & 1500 & 10 & 31 & 3.5 & 52 & 4 & 68 \\
\hline & 2500 & 17 & 38 & 6 & 60 & 7 & 74 \\
\hline
\end{tabular}

A sensitivity study of the maximum energy efficiency respectively, the maximum exergetic efficiency with respect to the compression ratio and maximum cycle temperature for various HEs effectiveness has been made. Therefore, the customer or designer can find the optimum value for the compression ratio in function of the maximum temperature allowed, depending on the performance (actually efficiencies) that he wants to get. No maximum energy efficiency with cogeneration was found.

\subsubsection{Case with the Recuperator Connected Downstream of the Useful Heat Exchanger}

Again, the temperature of the flue gases at the entrance of the recuperator, $T_{3}$, has to overcome the air temperature at its entrance, $T_{1}$. There is also an inferior limit for the water inlet temperature, $T_{u i}$, near of $455 \mathrm{~K}$. Same pressurized water inlet temperature in the useful heat exchanger was taken in all cases, with value of $490 \mathrm{~K}$. This choice allowed the comparison of all cases for the three configurations. Evolution of the inferior limit for $T_{u i}$ is available in [35] for various values of the effectiveness, variation range of the compression ratio and different maximum temperature of the cycle. The limit of $T_{u i}$ increases with the compression ratio and decreases with $T_{\max }$. Hence, if the customer wishes to introduce water at a lower temperature, he would choose a configuration with a lower compression ratio, and a higher $T_{\max }$. Moreover, the inferior limit of $T_{\max }$ for which the turbine produces a positive mechanical power is around $768 \mathrm{~K}$.

\section{Maximum Power Output, Energy and Exergy Rates}

Maximum values are available only for the power output, for all maximum temperature fixed values (Tab.4). At the optimum value of the compression ratio, one notices that the 

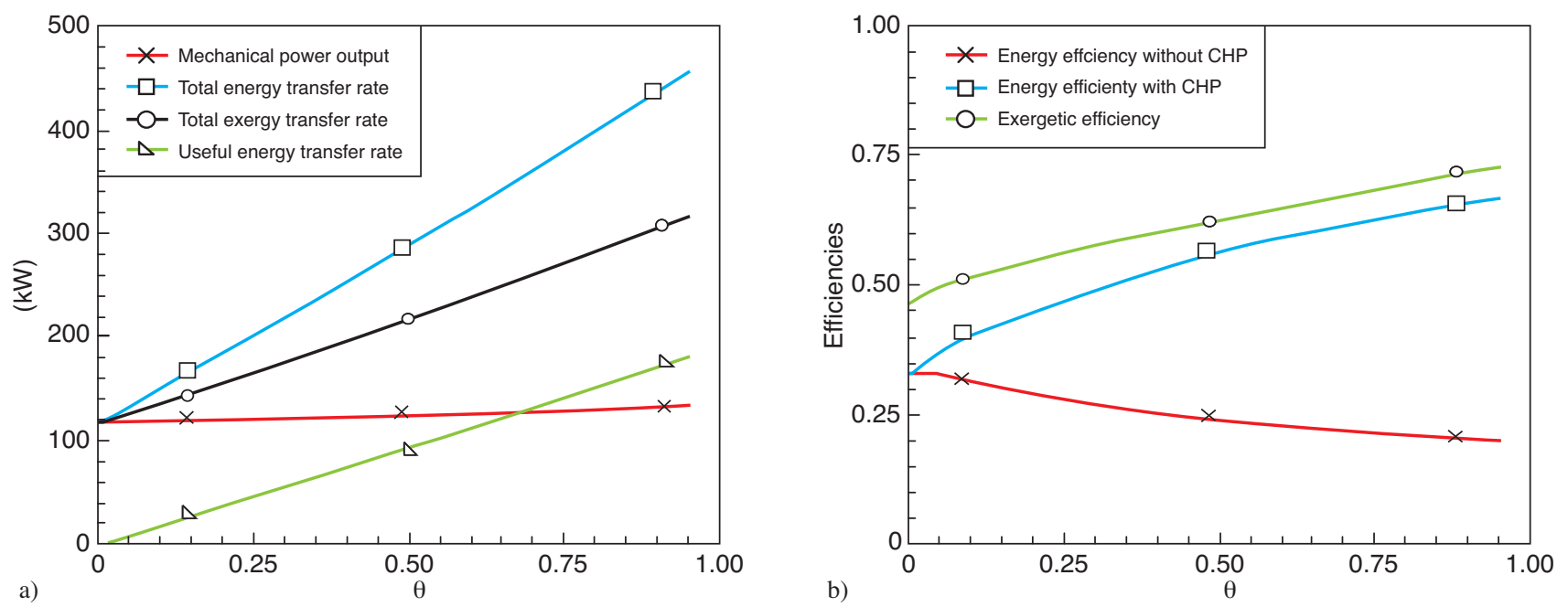

Figure 7

Evolution of a) energy and exergy rates, and b) efficiencies in function of $\theta$ ( $T_{\max }$ imposed, parallel configuration).

useful heat transfer rate is greater than the mechanical power, as HP ratio shows it. The heat/power ratio decreases as the maximum temperature of the cycle is increased.

The total energy transfer rate decreases monotonously with the compression ratio, as well as the total exergy transfer rate. These results confirm that the configuration where the useful heat exchanger is connected upstream of the recuperator is not a very attractive one.

\section{Efficiencies (Tab. 5)}

Only the energy efficiency without cogeneration shows maximum values in function of the compression ratio. The other efficiencies decrease with the increase of the compression ratio. Moreover the energy efficiency without cogeneration is visibly smaller than that for the previous configuration.

\subsubsection{Case with the Recuperator and the Useful Heat Exchanger are Connected in Parallel}

The inferior limit for the maximum temperature is computed for this new case, and its value was found equal to $720 \mathrm{~K}$, when $\theta=0.5$.

By comparing the results reported in Tables 4 and 5 for this case, one can see that all investigated energy rates and efficiencies present maximum values and that the first ones are obtained for higher compression ratio than the two others. Figure $7 \mathrm{a}$ shows that all energy and exergy rates increase with $\theta$, except the mechanical power output, which remains almost constant.

Same behavior is registered for the efficiencies (Fig. 7b), that are increasing with $\theta$, except the energy efficiency without cogeneration that decreases. The total heat transfer rate to the sink remains quasi constant whatever $\theta$ is.

\section{COMPARISON BETWEEN THE THREE MAINS CONFIGURATIONS OF THE GAS TURBINE COGENERATION SYSTEMS}

The comparison is carried out by keeping the model parameters constant (initial conditions previously indicated in Sect. 4.1.1), except the four main ones, namely fuel/air equivalence ratio, compression ratio, maximum temperature, and flue gases ratio going into the useful heat exchanger/heat recuperator, $\theta$. The comparison has been performed extensively [35]. We report here only the most significant results.

\subsection{Cogeneration with an Imposed Heat Transfer Rate from the Hot Source}

The configurations providing the highest mechanical power output are those where the heat recuperator is connected upstream of the useful heat exchanger, or the parallel configuration with $\theta=0$. If $\theta=1$ (all the flue gases are directed towards the useful HE), the least mechanical power output is obtained.

The useful heat transfer rate increases with the fuel/air equivalence ratio, and so does the mechanical power output. But the most powerful heat transfer rate configuration is that with the recuperator connected downstream, while the less powerful is that with the recuperator connected upstream. 

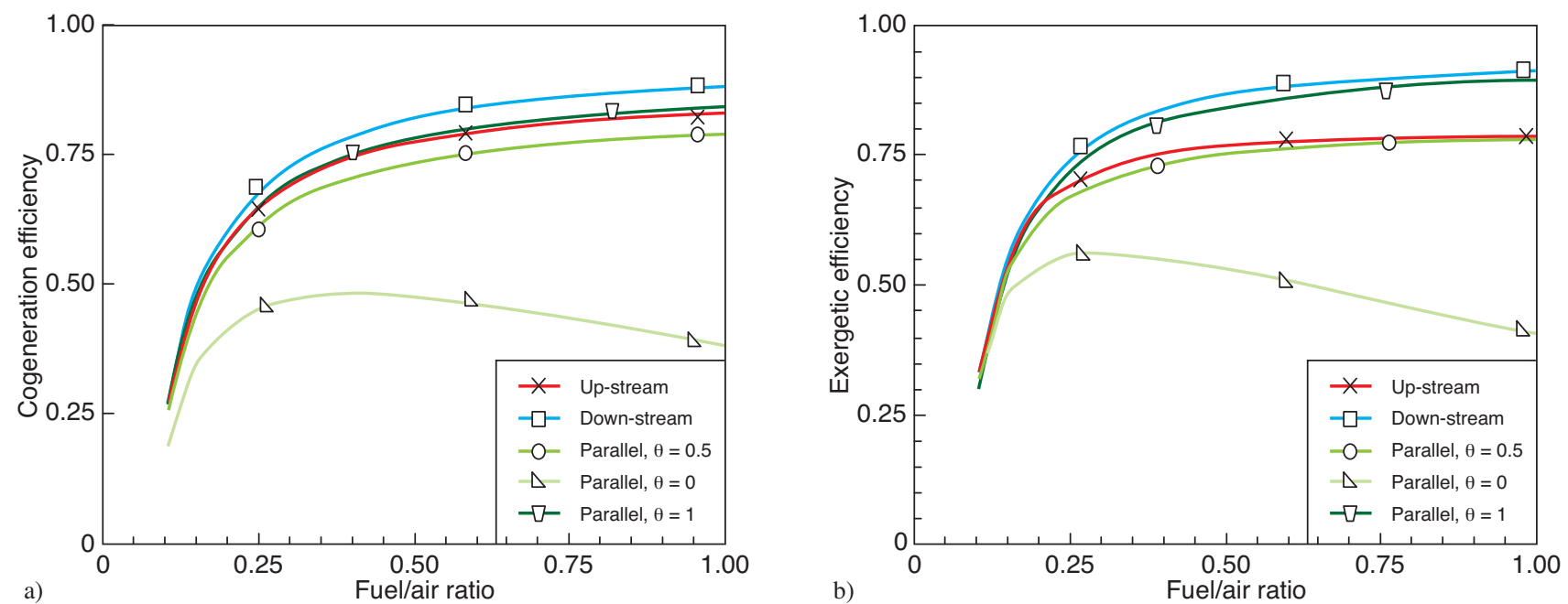

Figure 8

Comparison of the efficiency evolution in function of the fuel/air ratio (heat transfer rate imposed): a) energy efficiency with cogeneration, and b) exergetic efficiency, for the three configurations.
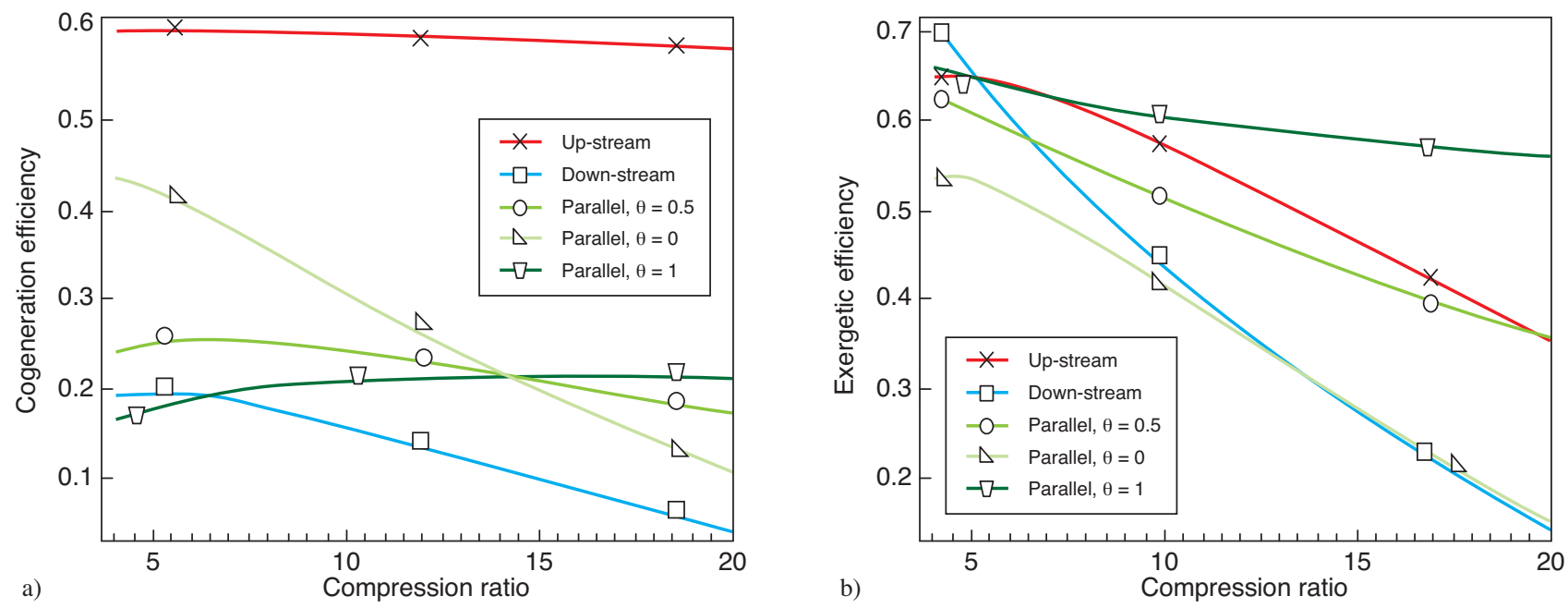

Figure 9

Comparison of the efficiency evolution in function of the compression ratio (heat transfer rate imposed):

a) energy efficiency with cogeneration, and b) exergetic efficiency, for the three configurations.

Figure 8 illustrates the efficiencies evolution in function of the fuel/air equivalence ratio.

These evolutions confirm the preceding results, and show that the first law cogeneration efficiency for the parallel configuration and $\theta=0$ is the less powerful one. The gain due to cogeneration is significant, whatever the heat utilization is.

Figure 9 shows the variation of the efficiencies with the compression ratio in order to determine what configuration suits better to the energy or exergy needs. From the first law point of view, the upstream recuperator configuration is always the best (Fig. 9a). On the other hand, if high exergetic efficiency is sought, the best choice would be the parallel configuration with $\theta=1$, if $\tau_{c}$ is greater than 7 (Fig. 9b). At small value of $\tau_{c}$ (less than 5), the downstream configuration seems better. For the intermediate situation, the upstream configuration is equivalent to the parallel one. 

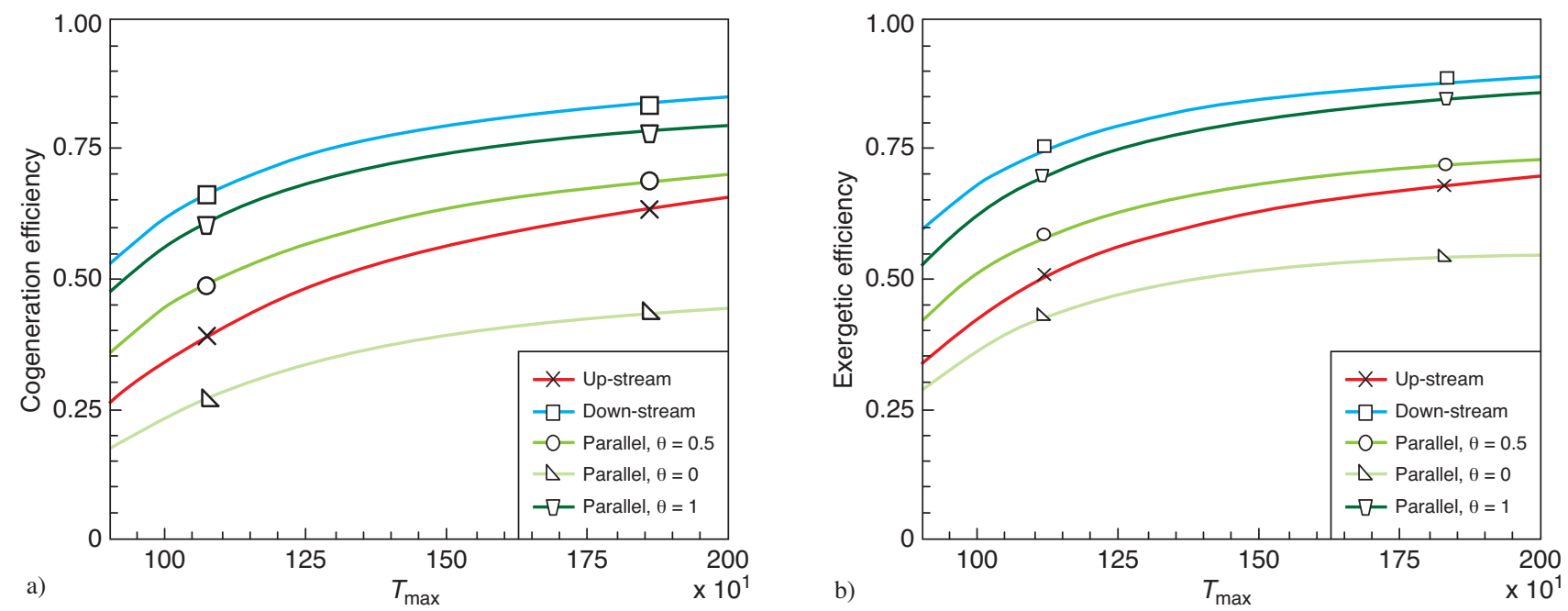

Figure 10

Comparison of the efficiency evolution in function of the cycle maximum temperature ( $T_{\max }$ imposed): a) energy efficiency with cogeneration, and b) exergetic efficiency, for the three configurations.

\subsection{Cogeneration with an Imposed Maximum Temperature of the Cycle}

As expected and shown in the above analysis, the mechanical power output and the useful heat transfer rate increase with the maximum allowable temperature. If downstream configuration is the worst from a mechanical point of view, it becomes the best choice from the useful heat transfer rate capability.

The evolution of the efficiencies in function of the maximum temperature gives a better idea of the differences between the 5 configurations (Fig. 10).

Higher values of the energy efficiency without cogeneration are registered for the equivalent upstream or parallel with $\theta=0$ configurations.

The first law cogeneration efficiency is the highest in the downstream configuration whatever $T_{\max }$ is. The same is valid for the exergetic efficiency. All these efficiencies are increasing with $T_{\max }$.

The sensitivity study with respect to the compression ratio has been performed. Its results show that for a chosen value of $T_{\max }(1500 \mathrm{~K})$, the energy efficiency with cogeneration is the best for the downstream configuration until $\tau_{c}=8$, then the upstream configuration shows higher values, for $\tau_{c}$ greater than 13.5. In the intermediate variation range of $\tau_{c}$, the parallel configuration with $\theta=1$ dominates.

An overview of the optimization results presented in Tables 2-5 clearly shows important differences between the optimal values of the system parameters corresponding to different optimization goals (power output, energy transfer rate, exergy transfer rate, efficiencies), for the two constraints imposed to the system.

\section{CONCLUSION}

A model of a regenerative open cycle Brayton engine with different configurations of the Gas Turbine system allowing cogeneration of heat and electricity is presented. The power output, total energy and exergy rates, together with the first law and second law efficiencies are optimized, when possible, with respect to several parameters, such as compression ratio, fuel/air equivalence ratio, and flue gases ratio going into the useful heat exchanger/heat recuperator. This optimization is separately performed for two constraints imposed to the system, namely the heat transfer rate released by the fuel combustion, respectively the cycle maximum temperature. Both of them are related to real operating conditions of the Gas Turbine system, and convey to optimum operational regimes of the system, but these optimum regimes are quite different.

The results are extremely sensitive to the imposed constraints. Thus, for an imposed heat transfer rate released by the fuel combustion, same optimal values of the compression ratio correspond to maximum power output, and maximum energy efficiency without cogeneration regimes, respectively to maximum total energy rate, and maximum first law cogeneration efficiency regimes. These results are accurate since the heat input is fixed. On the other hand, for the maximum exergy rate and maximum exergetic efficiency regimes the optimal values of the compression ratio are different. Hence, the maximum exergetic efficiency regime requires higher optimal values of the compression ratio than the maximum exergy rate one. Moreover, this conclusion is true for all three configurations, when the optimization is got. When a maximum cycle temperature is imposed, different optimal values of the performance yield for each maximum 
regime. Also, the energy rate optimization and first law cogeneration efficiency optimization are possible only for the parallel configuration of the heat exchangers. Finally, both constraints do not convey to exergy rate and exergetic efficiency optimization for the down-stream configuration. As both constraints are related to real operating conditions in Gas Turbine systems, these results could provide guidelines in the design stage of the system.

A comparison has been performed between the performance of the three configurations derived from the relative position of the recuperator and useful heat exchanger, namely up-stream, down-stream and the parallel connection. The last configuration has been studied for three different values of the ratio of flue gases going into the useful heat exchanger/heat recuperator, $\theta$ varying between $0,0.5$ and 1 , in order to demonstrate the importance of this parameter and the changes generated by its value. This comparison has been performed from an energetic and exergetic point of view and an accurate illustration is given. Each of the configurations that were studied has its strong points and highlights a certain performance of the system. Hence, the present model seems to be a powerful tool helping the customer to decide what design to choose for a specific application, or how to manage (control) an existing one. The exergetic efficiency is an interesting efficiency index that must probably be completed by the heat to power ratio. The most flexible situation seems to be the parallel configuration, even if it is not the one conveying to higher efficiencies. The studied configuration could be completed by a second parallel useful heat exchanger after the recuperator. This configuration would probably need to complete the study by an economic evaluation and criterion. It is one of the goals of future developments.

\section{ACKNOWLEDGMENTS}

The authors wish to thank the reviewers for their careful, equitable and constructive suggestions, which led to this revised manuscript.

\section{REFERENCES}

1 Descieux D., Feidt M. (2005) Etude de terrain sur la cogénération, Rapport d'expertise A.C. Énergie, GAT 9 du CNRS.

2 Radulescu M., Lottin O., Feidt M., Lombard C., Lenoc D., Ledoze S. (2006) Experimental Results with a Natural Gas Cogeneration System using a PEMFC, J. Power Sources 159, 2, 1142-1146.

3 www.snecma.com/IMG/swf/anim.swf (2007).

4 Sahin B., Kodal A., Ekmerçi I., Yilmaz T. (1997) Exergy Optimization for an Endoreversible Cogeneration Cycle, Int. J. Energy 22, 6, 551-557.

5 Butcher C.J., Reddy B.V. (2007) Second Law Analysis of Waste Heat Recovery based Power Generation System, Int. J. Heat Mass Trans. 50, 2355-2363.
6 Ust J.Y. (2007) Optimization of a Dual Cycle Cogeneration System based on a New Energetic Performance Criterion, Appl. Energy 84, 1079-1091.

7 Albrecht B.A., Kok J.B.W., Van Der Meer T.H. (2007) Coproduction of Synthesis Gas and Power by Integration of Partial Oxidation Reactor Gas Turbine and Air Separation Unit, Int. J. Exergy 4, 4, 357-370.

8 Rosen M.A., Hale V., Dincer I. (2004) Thermodynamics Assessment of an Integrated System and District Heating and Cooling, Int. J. Exergy 1, 1, 94-110.

9 Tyagi S.K., Wang S.W., Chen G.M., Wang Q., Chandra H., $\mathrm{Wu}$ C. (2007) Performance Investigation under Maximum Ecological and Maximum Economic Conditions of a Complex Brayton Cycle, Int. J. Exergy 4, 1, 98-116.

10 Tyagi S.K., Chen G.M., Wang Q., Kaushik S.C. (2006) Thermodynamic Analysis and Parametric Study of an Irreversible Regenerative Intercooled-Reheat Brayton Cycle, Int . J. Thermal Sci. 45, 829-840.

11 Al-Madani H. (2009) Effect of Thermodynamic and Mechanical Irreversibilities on Gas Turbine Performance Enhancement by Intake Air Cooling, Int. J. Exergy 6, 2, 166-180.

12 Khaliq A., Dincer I. (2011) Energetic and exergetic performance analyses of a combined heat and power plant with absorption inlet cooling and evaporative aftercooling, Energy 36, 5, 2662-2670.

13 Wang W., Chen L., Sun F., Wu C. (2005) Power Optimization of an Endoreversible Closed Intercooled Regenerated Brayton Cycle Coupled to Variable Temperature Reservoirs, Appl. Therm. Eng. 25, 1097-1113.

14 Wang W., Chen L., Sun F., Wu C. (2005) Power Optimization of an Endoreversible Closed Intercooled Regenerated Brayton Cycle, Int. J. Thermal Sci. 44, 89-94.

15 Khaliq A., Kahn T.A. (2007) Energetic and Exergetic Efficiency Analysis of an Indirect Fired Air Turbine Combined Heat and Power System, Int. J. Exergy 4, 1, 38-53.

16 Yari M., Sarabchi K. (2006) Optimization of the Part Flow Evaporative Gas Turbine Based on Exergy Method, Int. J. Exergy 3, 3, 291-304.

17 Kanoglu M., Dincer, I. (2009) Performance assessment of cogeneration plants, Energ. Convers. Manage. 50, 1, 76-81.

18 Balli O., Aras H. (2007) Energetic and exergetic performance evaluation of a combined heat and power system with the micro Gas Turbine (MGTCHP), Int. J. Energy Res. 31, 14, $1425-1440$

19 Dincer I., Rosen M.A. (2007) Exergy analysis of cogeneration and district energy systems, Exergy 257-276.

20 Biezma M.U., San Cristobal J.R. (2006) Investment Criteria for the Selection of Cogeneration Plants - A State of the Art Review, Appl. Therm. Eng. 26, 583-588.

21 Dumitrascu G., Horbaniuc B. (2010) Solar-Assisted JouleBrayton Engines used to Reduce Carbon Dioxide Emissions, Environ. Eng. Manage.J.9, 10, 1431-1435.

22 Ahmadi P., Dincer I. (2010) Exergoenvironmental analysis and optimization of a cogeneration plant system using Multimodal Genetic Algorithm (MGA), Energy 35, 12, 5161-5172.

$23 \mathrm{Wu}$ C., Kiang R.L. (1991) Power Performance of a Nonisentropic Brayton Cycle, J. Eng. Gas Turbine. Power 113, 4, 501-504.

24 Ferrière A. (2008) Centrales solaires thermodynamiques, Techniques de l'Ingénieur, BE 8093, 20 p.

25 Diao Z. (1994) Maximum Power Point Characteristics of a Closed Brayton Cycle, Paper 94 GT- 80 of International Gas Turbine and Aero Engine Congress and Exposition, The Hague, Netherlands, June 13-16. 
26 Feidt M. (1996) Optimisation d'un cycle de Brayton moteur en contact avec des capacités thermiques finies, Revue Générale de Thermique 418-419, 662-666.

27 Frutschi H.U. (2007) Closed-Cycle Gas Turbines, ASME Press.

28 Feidt M., Costea M., Postelnicu V. (2006) Comparaison entre le cycle simple de Brayton avec apport thermique imposé et avec contrainte de température maximale, Oil Gas Sci. Technol. - Rev. IFP 61, 2, 237-245.

29 Capata R., Sciubba E. (2006) Preliminary Considerations on the Thermodynamic Feasibility and Possible Design of Ultra, Micro and Nano Gas Turbines, Int. J. Thermo. 9, 2, 81-91.

30 Colombo L.P.M., Armanasco F., Perego O. (2007) Experimentation on a Cogenerative System Based on a Microturbine, Appl. Therm. Eng. 27, 705-711.

31 MacDonald C.F., Rogers C. (2008) Small Recuperated Ceramic Microturbine Demonstrator Concept, Appl. Therm. Eng. 28, 60-74.

32 Kanoglu M., Dincer I., Rosen M.A. (2007) Understanding energy and exergy efficiencies for improved energy management in power plants, Energy Policy 35, 3967-3978.
33 http://www.turbec.com/products/techspecific.htm

34 Heywood J.B. (1988) Internal Combustion Engine Fundamentals, McGraw-Hill, Singapore.

35 Alexandru G. (2007) Analysis and Modeling of Gas Turbine Engines, Internal Report, Université Henri Poincaré, Nancy, France.

36 Hao X., Zhang G. (2007) Maximum Useful Energy-Rate Analysis of an Endoreversible Joule-Brayton Cogeneration Cycle, Appl. Energy 84, 1092-1101.

37 Petre C., Feidt M., Costea M., Petrescu S. (2007) Optimization of the Direct Carnot Cycle, Appl. Therm. Eng. 27, 829-839.

38 Radcenco V., Vasilescu E.E., Popescu G., Apostol V. (2007) New Approach to Thermal Power Plants Operation Regimes Maximum Power Versus Maximum Efficiency, Int. J. Thermal Sci. 46, 12, 1259-1266. or distributed for profit or commercial advantage and that copies bear this notice and the full citation on the first page. Copyrights for components of this work owned by others than IFP Energies nouvelles must be honored. Abstracting with credit is permitted. To copy otherwise, to republish, to post on servers, or to redistribute to lists, requires prior specific permission and/or a fee: Request permission from Information Mission, IFP Energies nouvelles, fax. +33147527096, or revueogst@ifpen.fr. 